\title{
Levantamento das emissões atmosféricas da indústria da cerâmica vermelha no sul do estado de Santa Catarina, Brasil
}

\section{(Survey on atmospheric emissions from brick and tile kilns in southern Santa Catarina state, Brazil)}

\author{
V. F. Camara, H. M. Lisboa, L. Hoinaski, P. C. David \\ Departamento de Engenharia Sanitária e Ambiental da Universidade Federal de Santa Catarina - UFSC \\ vcntcamara@hotmail.com,h.lisboa@ufsc.br,leohoinaski@gmail.com,paulacunhadavid@gmail.com
}

\begin{abstract}
Resumo
Os principais contribuintes antropogênicos para a contaminação do ar são as emissões veiculares e industriais. Santa Catarina é um estado com setor industrial desenvolvido. Destaca-se não apenas pelo número, como também pela diversificação de atividades fabris. Dentre essas atividades, há a de produção de peças cerâmicas vermelhas (tijolos e telhas - as olarias). Há uma concentração representativa dessas empresas no sul desse estado. Suspeita-se que as emissões atmosféricas das olarias comprometam a qualidade do ar, de forma danosa a saúde da população. Entretanto, quase não foram realizados estudos aprofundados, nem da qualidade do ar, muito menos das emissões do setor. Esse trabalho visa verificar como é tratada a questão das emissões atmosféricas por parte das olarias. Tal levantamento foi realizado por duas maneiras: aplicação de questionários e levantamento de informações de licenciamento ambiental. Nos questionários, notou-se que apenas $13 \%$ das olarias afirmaram manter os seus equipamentos de tratamento de efluentes atmosféricos ativos durante todo o período da queima dos fornos. Na análise de documentos vinculados ao licenciamento ambiental, averiguou-se que uma grande parcela das olarias não realiza laudos de emissões, como também não verifica o adequado funcionamento dos seus equipamentos de controle de poluição atmosférica. Apesar dos laudos de emissão indicarem compatibilidade com os limites legais de emissão, a concentração dessas empresas em um espaço geográfico restrito indica que provavelmente haja impacto significativo na qualidade do ar.

Palavras-chave: poluição do ar, indústria da cerâmica vermelha, olarias, sul de Santa Catarina.
\end{abstract}

\begin{abstract}
The main anthropogenic contributions to air quality deterioration are through vehicular and industrial emissions. Santa Catarina is a Brazilian state with a developed industrial sector. The amount of industries, as well as their diversified activities stand out. Among these activities, there is the production of red clay ceramics (brick and tile kilns). There is a representative concentration of this kind of industries in southern Santa Catarina, Brazil, and the impact caused by these factories on air quality is a concern. There is a suspicion that this impact affect local population health. However, proper studies have not been done either on air quality or on these industries emissions. The aim of this work is to verify how the atmospheric emissions issue is considered by bricks and tile kilns. The survey was conducted applying two methods: questionnaire and evaluation of environmental assessment documents. In the questionnaires, it was noticed that only $13 \%$ of the kilns let their air pollution control devices on throughout the kiln operation. By the documents analysis it was verified that a significant amount of industries does not make stack sampling, as well as they do not verify if their air pollution control devices are properly working. Despite the fact that the emissions reports denote compatibility with local emission regulations, the density of factories in a small geographic space indicates that a significant impact on air quality occurs.
\end{abstract}

Keywords: air pollution, red clay ceramic industry, brick and tile kilns, southern Santa Catarina, Brazil.

\section{INTRODUÇÃO}

Emissões industriais e veiculares são as principais fontes de poluição atmosférica de origem antrópica em áreas urbanas. A Companhia Ambiental do estado de S. Paulo [1] estimou a contribuição de cada emissor para a poluição do ar na região metropolitana de S. Paulo, sendo que as indústrias e veículos foram os principais poluidores. Santa Catarina é o estado do Brasil com a maior concentração de indústrias per capita, com 29 indústrias para cada 10.000 habitantes [2]. Dentre os setores industriais, o de produtos cerâmicos destaca-se nesse estado, sendo responsável por $14,7 \%$ da produção nacional. São empregadas quase 15000 pessoas nesse setor em 714 estabelecimentos em todo o estado. Dessas indústrias, boa parte delas $(42,9 \%)$ é de micro ou pequenas empresas [3].

$\mathrm{O}$ processo de fabricação de tijolos e telhas segue, essencialmente, as seguintes etapas: extração de argila, sazonamento, preparação da massa, conformação, secagem e a queima. Os principais poluentes atmosféricos emitidos são o material particulado (MP), os óxidos de nitrogênio $\left(\mathrm{NO}_{\mathrm{x}}\right.$ ), os óxidos de enxofre $\left(\mathrm{SO}_{\mathrm{x}}\right)$, o monóxido de carbono $(\mathrm{CO})$, 
compostos clorados e fluoretados. A emissão de particulados ocorre tanto na manipulação e transporte da matéria-prima (emissões fugitivas) quanto pela queima nos fornos. Já a emissão dos gases ocorre devido à combustão e está vinculada à composição da matéria-prima e do combustível empregado [4]. Os óxidos de nitrogênio formam-se pela fixação térmica no nitrogênio atmosférico durante a queima, já os óxidos de enxofre são provenientes principalmente da constituição da matéria-prima (mas também podem se originar do combustível, no caso do emprego de carvão ou óleos). O monóxido de carbono é formado tanto pela combustão incompleta como pela dissociação de carbonatos da argila. Já emissão de compostos halogenados depende majoritariamente da composição da matéria-prima usada $[5,6]$.

Na Ásia, onde $87 \%$ da produção mundial de tijolos se concentram [7] as emissões atmosféricas provenientes da produção de cerâmica vermelha são um dos fatores determinantes para a deterioração da qualidade do ar $[8$, 9]. Isso se deve principalmente ao tipo de combustível empregado na queima, à tecnologia dos fornos e ao não emprego de tecnologias para a o controle da poluição do ar. Alguns elementos em comum podem ser verificados entre a produção de cerâmica vermelha no sul asiático e em Santa Catarina como: produção artesanal, fornos com tecnologia defasada, problemas de gestão, informalidade e predominância de fábricas de pequeno porte. [10-14]. No sul de Santa Catarina (Fig. 1) há uma importante concentração de uma parcela do setor cerâmico, responsável pela produção de tijolos e telhas. O Ministério do Trabalho e Emprego, por meio da Relação Anual de Informações Sociais (RAIS), aponta 318 empresas do ramo nessa região (para o ano de 2013). A região sul desse estado é a segunda mesorregião do Brasil com maior quantidade de indústrias desse setor (perdendo apenas para a de Campinas, SP) [15]. Como comparação, na Itália são 238 fábricas do setor, 183 na Alemanha, 150 em Portugal, 136 na França e 134 no Reino Unido [5].

Apesar de serem de pequeno porte, uma concentração de indústrias dessa magnitude pode levar a impactos ambientais consideráveis. Isso pode ocorrer, uma vez que os esforços legais de restrição de emissões estão principalmente focados em indústrias de grande porte. Portanto, a contribuição de pequenas fábricas para a deterioração da qualidade do ar pouco é conhecida [16].

Os municípios da região sul de Santa Catarina nos quais as olarias estão presentes, também apresentavam qualidade do ar que, quando da execução de monitoramento, excedia os padrões estabelecidos pelo Conselho Nacional do Meio Ambiente, por meio da resolução n. 3 de 1990 [17]. Apesar do monitoramento não ter sido feito com uma resolução temporal e espacial refinada, os padrões para os poluentes Particulado Total em Suspensão (PTS), Material Particulado Inalável $\left(\mathrm{MP}_{10}\right)$ e dióxido de enxofre $\left(\mathrm{SO}_{2}\right)$ foram superados frequentemente no período analisado [18].

As olarias do sul de Santa Catarina foram alvo de um Termo de Ajustamento de Conduta (TAC), por parte do

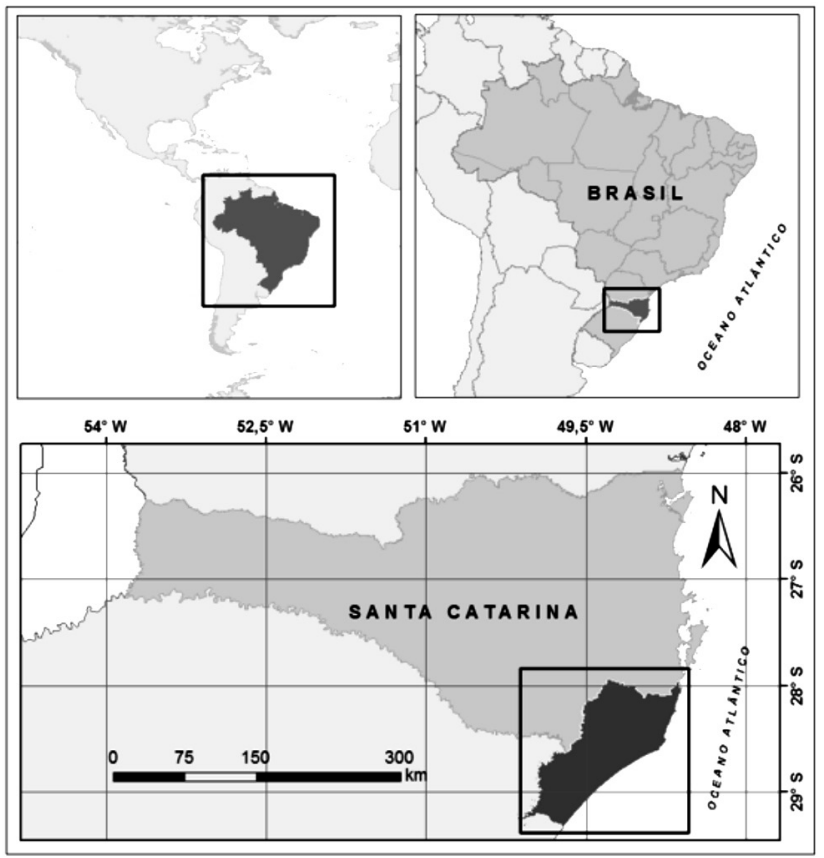

Figura 1: Localização da área estudada.

[Figure 1: Location of the studied area.]

Ministério Público Estadual, no ano de 2004. Este TAC tinha como um de seus objetivos a regularização das emissões atmosféricas [19]. Tal iniciativa foi feita por suspeitar-se da influência das emissões das olarias na qualidade do ar da região.

Nesse trabalho, foi feito um levantamento sobre as emissões atmosféricas das indústrias de cerâmica vermelha (olarias) no sul de Santa Catarina. Para tal, foi aplicado um questionário, como também foram analisados os laudos de emissões atmosféricas, documentos vinculados ao licenciamento ambiental dessas indústrias.

\section{MÉTODOS}

As informações foram coletadas de duas maneiras: por um questionário e pela avaliação de documentos do licenciamento ambiental. Primeiramente, aplicou-se um questionário a 71 olarias entre janeiro e dezembro de 2012. O questionário consistiu em 17 perguntas, separadas em três assuntos diferentes. As primeiras perguntas tinham como objetivo averiguar informações sobre o tratamento de gases: se a olaria possuía algum tipo de tratamento de gases, qual o tipo, custo, motivo de instalação, se o equipamento apresentava problemas, qual a frequência deles, se a fabricante fornece assistência técnica e se o projeto do sistema de tratamento existia. A segunda bateria de perguntas levantou informações sobre a parte operacional da olaria: qual o combustível empregado, a sua quantidade, o número de fornos, a ocupação semanal dos fornos, se o equipamento de controle funciona durante toda a queima. Por último foi questionado sobre aspectos vinculados ao licenciamento ambiental: se a empresa realiza o auto-monitoramento de emissões, se as licenças ambientais estão em situação regular, 
Tabela I - Classificação das olarias.

[Table I - Brick and tiles kilns categorization.]

\begin{tabular}{cccccc}
\hline Grupo & A & B & C & D & Total \\
\hline Produção Mensal de Peças & Maior & Entre 400.000 & Entre 200.000 & Até 200.000 & \\
Olarias Produtoras de Tijolos & 600.000 & e 600.000 & e 400.000 & & \\
(Percentual) & 3 & 7 & 66 & 23 & 99 \\
Olarias Produtoras de Telhas & $(3,0 \%)$ & $(7,1 \%)$ & $(66,7 \%)$ & $(23,2 \%)$ & $(100 \%)$ \\
(Percentual) & 3 & 4 & 12 & 13 & 32 \\
& $(9,4 \%)$ & $(12,5 \%)$ & $(37,5 \%)$ & $(40,6 \%)$ & $(100 \%)$ \\
\hline
\end{tabular}

se a olaria foi notificada alguma vez devido às emissões atmosféricas e se os empreendedores consideram que as olarias poluem o ar da região. Esse questionário foi aplicado exclusivamente nos municípios com maior número de olarias: Morro da Fumaça (51\% dos questionários), Sangão (31\%) e Içara $(18 \%)$.

Em um segundo momento foram levantados dados em documentos cedidos por duas regionais da Fundação Estadual do Meio Ambiente de Santa Catarina (FATMA), órgão responsável pelo licenciamento ambiental na região. Ao todo, mais de 3600 páginas de documentos foram digitalizadas e estudadas, resultando na compilação dos dados de 151 empresas do setor. Esse levantamento ocorreu entre janeiro e dezembro de 2012.

As olarias foram classificadas em quatro grupos, de acordo com a produção. Essa classificação foi realizada para verificar eventuais tendências no estudo, e é demonstrada na Tabela I.

\section{RESULTADOS E DISCUSSÃO}

Quanto aos questionários, das 71 empresas interrogadas, $60(87 \%)$ afirmaram possuir algum tipo de Equipamento de Controle de Emissões Atmosféricas (ECPA). Dessas empresas, 22 reportaram a ocorrência de problemas com a operação desses equipamentos, sendo que a maioria indicou a ocorrência diária desses inconvenientes. Quanto à existência de projetos dos ECPA, 38 (63\%) das olarias entrevistadas disseram não possuir nenhum. Ainda se referindo ao ECPA, sobre o período de funcionamento dos mesmos durante a realização da queima nos fornos, das 60 olarias com algum tipo de equipamento, apenas 9 (16\%) mantém os mesmos em atividade durante toda a etapa de queima dos fornos. A maior parte delas (32, ou 53\%) afirmou deixar os ECPA em funcionamento entre 5 e $50 \%$ do período em que os fornos estão em atividade. Sobre o tipo de combustível empregado na queima dos fornos. Quase a totalidade das indústrias afirmou empregar madeira ou seus derivados nos fornos (67 delas ou $97 \%$ ).

$\mathrm{Na}$ análise dos documentos, verificou-se uma predominância de olarias de pequeno porte, seja na produção de telhas, seja na produção de tijolos. Quanto à localização geográfica, notou-se uma concentração das olarias. Três cidades (Morro da Fumaça, Sangão e Içara) concentraram quase $79 \%$ das olarias pesquisadas. Tal informação é ilustrada na Fig. 2.

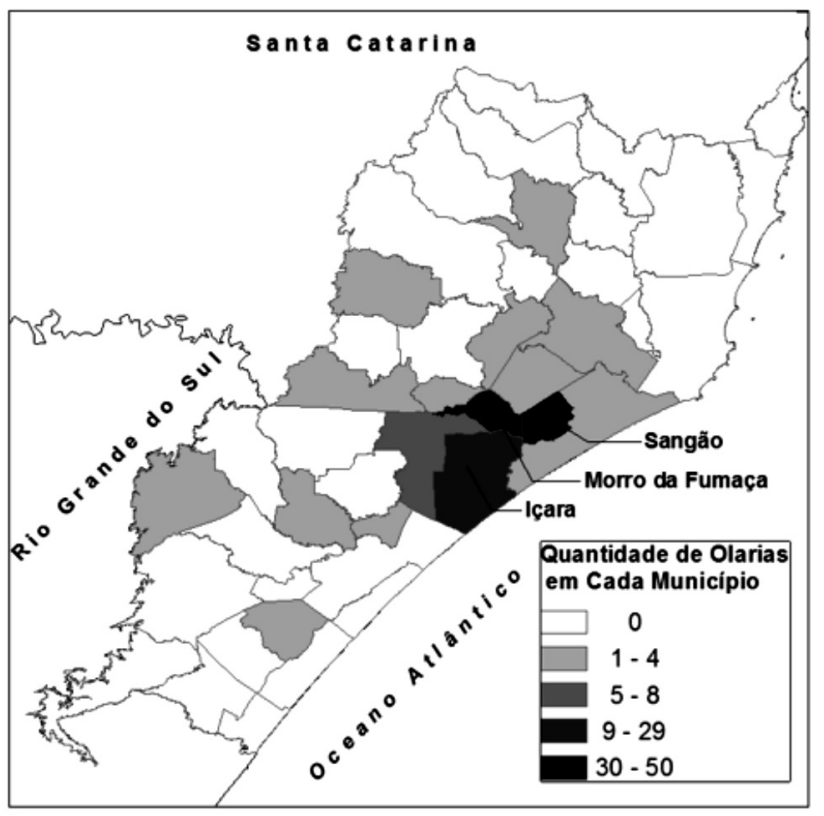

Figura 2: Distribuição espacial das olarias no sul de Santa Catarina.

[Figure 2: Distribution of kilns at southern Santa Catarina, Brazil.]

Quanto aos produtos, 66\% das olarias produzem tijolos e $21 \%$ telhas, o restante produzia conjuntamente os dois produtos. Como dito anteriormente, há uma predominância das olarias de menor porte. Essas olarias também são as responsáveis pela maior parte da produção. Essa informação pode ser confirmada na Tabela II.

Uma parcela considerável (41\%) dos responsáveis pelas fábricas afirma, nos documentos disponíveis na FATMA (órgão licenciador), possuir algum Equipamento de Controle de Poluição Atmosférica (ECPA), sendo que o lavador de gases é o mais utilizado (em 61 das 62 empresas que declararam tratar os gases). Apenas $44 \%$ das empresas possuíam algum laudo de emissões atmosféricas. Desses laudos, um terço deles não permitia avaliar a eficiência de captura de poluentes dos ECPA. Quando avaliadas, as eficiências demonstravam um desempenho médio na remoção de contaminantes de $62 \%$ para o material particulado e de $33 \%$ para os óxidos de enxofre.

Nenhuma olaria ultrapassou o limite de emissão 
Tabela II - Produção das olarias de acordo com o porte.

[Table II - Kilns production regarding their size.]

\begin{tabular}{|c|c|c|c|c|c|}
\hline Grupo & A & B & $\mathrm{C}$ & D & Total \\
\hline $\begin{array}{c}\text { Tijolos produzidos } \\
\text { por mês } \\
\text { (Percentual da } \\
\text { produção total) }\end{array}$ & $\begin{array}{c}3.500 .000 \\
(11,6 \%)\end{array}$ & $\begin{array}{c}3.800 .000 \\
(12,6 \%)\end{array}$ & $\begin{array}{c}19.617 .000 \\
(65,0 \%)\end{array}$ & $\begin{array}{c}3.265 .000 \\
(10,8 \%)\end{array}$ & $\begin{array}{c}30.182 .000 \\
(100 \%)\end{array}$ \\
\hline $\begin{array}{c}\text { Telhas produzidas } \\
\text { por mês } \\
\text { (Percentual da } \\
\text { produção total) }\end{array}$ & $\begin{array}{c}2.330 .000 \\
(24,3 \%)\end{array}$ & $\begin{array}{c}1.980 .000 \\
(20,9 \%)\end{array}$ & $\begin{array}{c}3.394 .000 \\
(35,9 \%)\end{array}$ & $\begin{array}{c}1.785 .000 \\
(18,9 \%)\end{array}$ & $\begin{array}{c}9.459 .000 \\
(100 \%)\end{array}$ \\
\hline
\end{tabular}

impostos pelas resoluções do Conselho Nacional do Meio Ambiente (CONAMA) n. 382/2006 e 436/2011 [20, 21] para o material particulado (único poluente regulamentado pelas resoluções que é mensurado nos laudos). Tal limite é de 730 $\mathrm{mg} / \mathrm{Nm}^{3}$. Como comparação, o valor médio da concentração de Material Particulado (MP) encontrado nos laudos das olarias foi de $75,9 \mathrm{mg} / \mathrm{Nm}^{3}$ (66 laudos analisados), sendo que a União Europeia [5] estabeleceu como objetivo, no seu guia de melhores tecnologias disponíveis para o setor da cerâmica, o valor de até $20 \mathrm{mg} / \mathrm{Nm}^{3}$ para o $\mathrm{MP}$, com a aplicação de medidas primárias (substituição de combustível sólido por líquido ou gasoso) e secundárias (uso de filtro manga e absorvedores recheados). Já a concentração média de $\mathrm{SO}_{\mathrm{x}}$ encontrada nos laudos foi de $31,4 \mathrm{mg} / \mathrm{Nm}^{3}$. O fato das emissões não ultrapassarem os limites legais não significa que não haja impacto na qualidade do ar local e consequentemente, na saúde da população. Estudos de dispersão e de monitoramento da qualidade do ar deveriam ser aplicados para fornecer mais subsídios a essa discussão, pois a bacia aérea da região pode já estar saturada por conta do acúmulo de emissões em uma área restrita. Considerando a emissão de material particulado das olarias, é possível fazer uma comparação com a das indústrias da Região Metropolitana de São Paulo (RMSP), extraídas do Relatório de Qualidade do Ar [1]. A emissão das olarias catalogadas pela FATMA seria equivalente a $6 \%$ das emissões de

Tabela III - Comparação de emissões de material particulado na RMSP vs. olarias do sul de Santa Catarina.

[Table III - Comparison among particulate matter emissions in S. Paulo Metropolitan Area vs. kilns in Southern Santa Catarina, Brazil.]

\begin{tabular}{cccc}
\hline & $\begin{array}{c}\text { Emissão MP } \\
\left(\mathrm{t} . \mathrm{ano}^{-1}\right)\end{array}$ & $\begin{array}{c}\text { Emissão MP } \\
\text { por área } \\
\left(\mathrm{t} . a n o^{-1} \cdot \mathrm{km}^{-2}\right)\end{array}$ & $\begin{array}{c}\text { Emissão MP } \\
\text { por indústria } \\
\left(\mathrm{t} . a n o^{-1}\right)\end{array}$ \\
\hline $\begin{array}{c}\text { Fontes Fixas } \\
\text { RMSP } \\
\begin{array}{c}\text { Olarias } \\
\text { Sul de SC }\end{array}\end{array}$ & 3.060 & 0,385 & 15,45 \\
\hline
\end{tabular}

Nota: Foram considerados os dados apenas dos municipios de Morro da Fumaça, Içara e Sangão. material particulado das fontes fixas inventariadas na RMSP. Isso com dados de emissão de apenas 67 das 151 olarias. Fazendo uma extrapolação, utilizando a emissão média para os dados faltantes, chega-se a um valor de 425,3 t/ano, ou $14 \%$ das emissões fixas na RMSP. A Tabela III demonstra uma comparação para os dados de emissão das três cidades com maior número de olarias, considerando valores médios de emissão para os dados inexistentes.

Quanto aos óxidos de enxofre, apesar da queima da madeira não gerar emissões representativas devido ao seu baixo teor de enxofre [22] a emissão está atrelada a constituição da argila empregada no processo [5].

\section{CONCLUSÕES}

Verificou-se por meio do questionário que a maioria das olarias não ativa os seus ECPA durante a totalidade do período da queima dos fornos. Notou-se que boa parte dos ECPA não possui projeto. Os dados levantados junto aos documentos conjuntamente com essa informação do questionário indicam uma inadequação técnica dos equipamentos empregados para o tratamento das emissões atmosféricas (baixa eficiência de remoção, conjuntamente com o registro de problemas no funcionamento dos equipamentos). Em campo, notou-se que diversos dos lavadores empregados eram construídos pelas próprias empresas (em alvenaria) visando se adequar às demandas do TAC, em detrimento do emprego de tecnologias adequadas. Um fato notável averiguado através do questionário foi de que apenas 9 das 60 olarias questionadas afirmaram manter o tratamento de efluentes atmosféricos durante toda a atividade de queima do forno. Por meio dessa constatação, pode-se afirmar que empresas acreditam que as emissões atmosféricas ocorrem exclusivamente durante algumas etapas da queima. A emissão absoluta de MP das olarias é inferior às registradas na RMSP, mas apresenta-se representativa quando se considera a distribuição geográfica das indústrias. A concentração de emissões é quase o dobro da encontrada em uma região que é densamente industrializada $\left(0,703\right.$ t.ano ${ }^{-1} \mathrm{~km}^{-2}$ no sul de SC contra 0,385 t.ano ${ }^{-1} \mathrm{~km}^{-2}$ na região metropolitana de São Paulo). Apesar de não haver nenhum estudo conclusivo, que determine a real influência das olarias na qualidade do ar (nem pelo monitoramento, muito menos de modelagem de 
dispersão dos poluentes), existem alguns indícios de que um impacto na qualidade do ar da região existe. As principais evidências são: a concentração de indústrias na região e a falta de controle adequado das emissões atmosféricas. $\mathrm{O}$ TAC que foi assinado, apesar de ter feito as indústrias da cerâmica vermelha derem atenção às emissões atmosféricas, foi uma ação pontual que não teve uma continuidade. Há também uma série de fatores a serem contabilizados: o mau assessoramento ambiental recebido pelas empresas (verificado na análise dos documentos apresentados ao órgão licenciador), a brandura da legislação (que não estabelece limites de emissão específicos para o setor) e a falta de uma base de dados que auxilie no planejamento regional (tanto da qualidade do ar quanto das emissões). A despeito das exigências do estado as empresas de pequeno porte não possuem condições financeiras de arcar com custos para a realização de estudos ambientais mais elaborados. $\mathrm{O}$ condicionamento da emissão de licenças somente à comprovação de eficiência dos ECPA ou do atendimento dos limites de emissão, não exige respaldo técnico (presença de projeto e garantia de eficiência) dos ECPA. Esse trabalho levou em consideração apenas um dos fatores determinantes da poluição atmosférica (as emissões). Uma avaliação que considere outros aspectos (como a topografia e a meteorologia) deve ser feita. Os resultados também indicam que as regulamentações de emissão de poluentes não atendem às demandas para a manutenção da qualidade do ar. Em regiões com elevada densidade de indústrias, parâmetros mais restritivos deveriam ser adotados, uma vez que os estados têm autonomia para estabelecer limites de emissões mais restritivos [20]. Atualmente não há regulamentação nacional específica que limite as emissões das olarias: são aplicados os limites referentes à combustão externa de derivados de madeira das resoluções CONAMA 436/2011 e $382 / 2006$. Além disso, na faixa de potência térmica nominal que elas operam, não há limites nem para a emissão de óxidos de nitrogênio (importante poluente proveniente da combustão), nem para os óxidos de enxofre, muito menos para os compostos clorados e fluoretados. Países asiáticos onde a emissão dessas indústrias é expressiva já possuem regulamentação específica para as emissões atmosféricas das olarias $[16,23]$. Diversas medidas podem ser aplicadas para a redução do impacto atmosférico das olarias: o emprego de tratamento adequado às emissões atmosféricas, utilizando tecnologias como os filtros de manga e absorvedores, a substituição para combustíveis menos poluentes (como o gás natural) e a modernização dos fornos.

\section{AGRADECIMENTOS}

À Fundação do Meio Ambiente de Santa Catarina (FATMA), pela cessão dos documentos. Aos bolsistas do Laboratório de Controle de Qualidade do Ar.

\section{REFERÊNCIAS}

[1] Companhia Ambiental do Estado de S. Paulo (CETESB),
"Qualidade do ar no estado de S. Paulo 2013, 2014", disponível em <http://www.cetesb.sp.gov.br/ar/qualidadedo-ar/ 31-publicacoes-e-relatorios>, acesso em 15/07/2014.

[2] Instituto Brasileiro de Geografia e Estatística (IBGE), Pesquisa Industrial 2011, 2013, disponível em

$<\mathrm{ftp}: / / \mathrm{ftp}$. ibge.gov.br/Industrias_Extrativas_e_de Transformacao/Pesquisa_Industrial_Anual/Empresa 2011 / piaempresa2011.pdf $>$, acesso em 10/06/2014.

[3] Federação das Indústrias do Estado de Santa Catarina (FIESC), Santa Catarina em Dados. 2013. Disponível em $<$ http:// www2.fiescnet.com.br/web/recursos/VUVSR016a3pPQT09>. Acesso em 13/07/2014.

[4] United States Environmental Protection Agency (USEPA) AP 42 - Compilation of Air Pollutant Emission Factors, Capítulo 11, Seção 3 - Bricks and Related Clay Products (1997). Disponível em:

$<$ http://www.epa.gov/ttnchie1/ap42/ch11/final/c11s03.pdf . Acesso em: 05 de outubro de 2014.

[5] União Europeia (UE), "Reference Document on Best Available Techniques in the Ceramic Manufacturing Industry" (2007). Disponível em: <http://eippcb.jrc. ec.europa.eu/reference/BREF/cer_bref_0807.pdf $>$. Acesso em: 06/10/2014.

[6] Regional Energy Resources Information Center (RERIC), "Small and medium scale industries in Asia: Energy and environment, brick and ceramic sectors" (2003).

[7] C. Weyant, V. Athalye, S. Ragavan, U. Rajarathnam, D. Lalchandani, S. Maithel, E. Baum, T. Bond,

Environmental Science \& Technology 48, 11 (2014) 64776483.

[8] M. Ahmad, L. van den Berg, H. Shah, T. Masood, P. Büker, L. Emberson, M. Ashmore, Environmental Pollution 162 (2012) 319-324.

[9] S. Guttikunda, B. Begun, Z. Wadud. Air Quality, Atmosphere Health 6, 2 (2013) 357-365.

[10] World Bank, Introducing Energy-Efficient Clean Technologies in the Brick Sector of Bangladesh (2011) Disponível em: <https://openknowledge.worldbank.org/ bitstream/handle/10986/2797/601550ESW0P1110e002011 00Color0FINAL.pdf $>$. Acesso em 01/11/2014.

[11] C. Schmidt, Environmental Health Perspectives 121, 8 (2013) 242-249.

[12] Climate and Clean Air Coalition (CCAC), Annual Report September 2013 - August 2014. 2014. Disponível em: $<$ http://ccacoalition.org/docs/pdf/CCAC_Annual_ Report_2013-2014.pdf $>$, acesso em 20/10/2014

[13] Y. Cunha, "Aspectos da paisagem oleira de Morro da Fumaça (SC)", Diss. Mestrado, Universidade Federal de Santa Catarina, Centro de Filosofia e Ciências Humanas, Programa de Pós-Graduação em Geografia, Florianópolis, SC (2002), disponível em: < http://repositorio.ufsc.br/xmlui/ handle/123456789/84322>, acesso em 03/10/2014.

[14] R. Redivo, "Uma análise da gestão de empresas produtoras de cerâmica vermelha do sul de Santa Catarina", Diss. Mestrado, Universidade Federal de Santa Catarina, Centro Tecnológico, Programa de Pós-Graduação em Engenharia de Produção, Florianópolis, SC (2007), 
disponível em <http://tede.ufsc.br/ teses/PEPS5121.pdf>, acesso em 01/11/2014.

[15] Brasil, Ministério do Trabalho e Emprego, Anual de Informações Sociais (2013). Disponível em:

$<$ http://bi.mte.gov.br/bgcaged/>. Acesso em 10 de outubro de 2014.

[16] H. Co, N. Dung, H. Le, D. An, K. Chinh, N. Oanh, Int.1 J. Environmental Studies 66, 1 (2009) 113-124.

[17] Conselho Nacional do Meio Ambiente (CONAMA), Resolução no 03 de 28/06/1990, disponível em <http://www. mma.gov.br/port/conama/res/res90/res0390.html>, acesso em 22/10/2014.

[18] T. Souza, P. Pavei, Tecnologia Ambiente 16 (2010) $1-21$.

[19] Santa Catarina, Ministério Público Estadual, "Programa de Prevenção e Repressão e Prevenção à
Poluição Atmosférica", 18/01/2007, disponível em <http:// www.mp.sc.gov.br/portal/site/conteudo/cao/cme/atividades/ poluicao_atmosferica/olarias.doc>, acesso em 27/06/2014. [20] Conselho Nacional do Meio Ambiente (CONAMA), Resolução 382 de 26/12/2006, disponível em <http:// www. mma.gov.br/port/conama/legiabre.cfm? codlegi $=520>$, acesso em 22/10/2014.

[21] Conselho Nacional do Meio Ambiente (CONAMA), Resolução 436 de 22/12/2011, disponível em <http:// www. mma.gov.br/port/conama/legiabre.cfm? codlegi $=660>$, acesso em $22 / 10 /$.

[22] W. Quirino, A. do Vale, A. Andrade, V. Abreu, A. Azevedo. Biomassa \& Energia 1, 2 (2004) 173-182.

[23] U. Rajarathnam, V. Athalye, S. Ragavan, S. Maithel, D. Lalchandani, S. Kumar, E. Baum, C. Weyant, T. Bond, Atmospheric Environment 98 (2014) 549-553.

(Rec. 04/09/2014, Rev. 19/11/2014, Ac. 04/03/2015) 